\title{
Developmental Language Disorders: Challenges and Implications of Cross-Group Comparisons
}

\author{
Susan Ellis Weismer \\ Department of Communication Sciences and Disorders/Waisman Center, University of Wisconsin-Madison, \\ Madison, Wisc., USA
}

\section{Key Words}

Developmental language disorders · Cross-group comparison · Specific language impairment · Autism spectrum disorders

\begin{abstract}
Historically, specific language impairment (SLI) and language deficits associated with autism spectrum disorders (ASD) have been viewed as distinct developmental language disorders. However, over the last decade or so, a considerable amount of research has explored general similarities or specific areas of overlap between children with SLI and ASD based on language and cognitive profiles, neuroimaging findings, and genetic research. The clinical classification schemes that are used to identify the children necessarily influence the extent to which SLI and ASD are viewed as overlapping or distinct conditions. Yet, the criteria used to diagnose these two populations vary across countries and even across investigators within a given country. This necessarily impacts the findings from comparative investigations of these groups. With these challenges in mind, clinical implications of evidence for similarities and distinctions between children with SLI and ASD will be discussed with respect to differential diagnosis and treatment.
\end{abstract}

(c) 2013 S. Karger AG, Basel

\section{KARGER}

(c) 2013 S. Karger AG, Basel

$1021-7762 / 13 / 0652-0068 \$ 38.00 / 0$

E-Mail karger@karger.com

www.karger.com/fpl

\section{Introduction}

There has been an increased interest recently in the extent to which specific language impairment (SLI) overlaps with autism spectrum disorders (ASD), even though historically these two neurodevelopmental disorders were seen as quite distinct. SLI is typically defined as a developmental language disorder that is associated with no known sensory, neurological, intellectual, or emotional deficits [1-3]. Autism involves deficits in social interaction, communication, and restricted and repetitive behaviors and interests, with a spectrum of conditions ranging from autistic disorder (AD) to Asperger's syndrome [4]. Both of these disorders are extremely heterogeneous in nature. Most children with SLI have deficits in structural language (phonology, semantics, morphology, syntax), but others have relatively more difficulty with pragmatic aspects (social use) of language [5]. Children whose primary difficulties involve pragmatic aspects of language and communication rather than structural language have been referred to as having pragmatic language impairment (PLI) $[6,7]$. Similarly, in addition to variability in other defining features of autism and comorbid conditions (e.g. intellectual disability), children on the autism spectrum display considerable variation in language and communication skills $[8,9]$. Deficits in pragmatics are closely linked to difficulties in social in- 
teraction and are often viewed as a universal aspect of ASD. However, some individuals with ASD display structural language deficits that mimic those of SLI, while others do not, leading to designations of ASD-LI (language impaired) and ASD-LN (language normal). Thus, although core defining criteria of SLI and autism differ, it is at these intersections of subgroups within the larger populations that questions of overlap arise - that is, PLI overlaps with autism spectrum features and ASD-LI overlaps with SLI.

\section{Examination of SLI-ASD Overlap}

The overlap between children with SLI and ASD will be considered based on their phenotypes (i.e. language and cognitive profiles), neuroimaging findings, and genetic research. Claims regarding language overlaps for a subset of children with SLI and ASD have focused on similarities in social communication or pragmatic aspects of language as well as on structural language components. Cognitive profiles have been compared at a broad level in terms of the discrepancy between nonverbal cognition and language levels observed in SLI and a subset of children with ASD. Specific aspects of cognitive functioning (e.g. theory of mind, executive function) have also been compared in the two diagnostic groups. As reviewed below, comparisons have been made from the perspective of clinical markers of SLI (e.g. nonword repetition deficits) in children with ASD, and conversely from the viewpoint of defining features of autism (e.g. performance on autism diagnostic measures) in children with SLI.

\section{Evidence regarding Phenotypes}

Although the question of possible overlap between SLI and autism has a long history $[10,11]$, this issue has sparked a vigorous debate in the literature that has escalated within the last 10 to 15 years. One proposed source of phenotypic overlap between SLI and ASD is in the area of pragmatics or social use of language. As noted previously, a subset of children with SLI has been identified as having PLI whose primary difficulties are with the use of language in context rather than core structural impairments in grammar, phonology, or vocabulary $[12,13]$. Children with PLI have been characterized as displaying difficulties with topic maintenance, discourse comprehension, abstract language, semantic specificity, and sensitivity to the needs of their conversational partners [14, 15]. While Bishop and Norbury [6] demonstrated that children with PLI did not meet the more stringent criteria for $\mathrm{AD}$, there has been a good deal of discussion about how best to conceptualize this subgroup of children and the relation between SLI and the broader autism spectrum $[16,17]$. Complicating the investigation of this issue are the shifting diagnostic boundaries between SLI and pervasive developmental disorders [18], as well as reports of actual evolution of social communication deficits and autistic features over development in children with a history of SLI [19].

Research has also explored the extent to which structural language deficits in a subset of children with ASD are similar to those seen in SLI, with a number of studies providing evidence of phenotypic overlap [20-24]. For example, both children with SLI and children with ASDLI often omit tense-marking morphemes (especially English speakers) and display deficits in phonological processing/memory span as indexed by nonword repetition tasks $[21,23]$. Deficits in marking tense have been proposed as a clinical marker of SLI [25], as have deficits in nonword repetition [26]. That is, both of these patterns of difficulty are central to the characterization of SLI, so it is particularly notable for these areas to be problematic in ASD-LI as well. Further evidence of overlap in the language phenotype comes from an investigation by McGregor et al. [27], in which they found similar patterns of cross-domain (i.e. lexical-syntactic) associations for children with SLI and children with ASD-LI. Similar patterns of lexical-grammatical development have also been observed in toddlers with ASD and late-talking toddlers without autism (who may be at risk of SLI) [28].

On the other hand, it is definitely not the case that all results are consistent in supporting the claim of structural language similarities between children with SLI and children on the autism spectrum who have language impairment. Williams et al. [29] have argued that the research evidence does not support commonalities in language phenotypes across these groups, noting that even though behavioral similarities might be observed at a given point in development, it is important to consider differences in the overall trajectories in language development for these populations (also see Charman [30] regarding individualgrowth trajectories across development in autism). With respect to particular aspects of structural language, both groups have deficits in phonological processing/short-term memory as indexed by nonword repetition; however, they have been shown to display different error patterns $[31,32]$. In a recent study, nonword repetition abilities were compared in children with SLI, 
children with ASD-LI, and typical controls matched on verbal mental age [33]. Nonword stimuli were manipulated with respect to stimulus length, consonant cluster position, and wordlikeness. Findings revealed significant differences between the SLI and ASD-LI groups in terms of level of accuracy and error types, while the ASD-LI group performed similarly to the language-matched children with typical development. Williams et al. [33] argue that these findings indicate that different cognitive factors underlie difficulties in nonword repetition in SLI and ASD-LI. Demouy et al. [34] examined language characteristics of French-speaking children with $\mathrm{AD}$, pervasive developmental disorder not otherwise specified (PDDNOS), and SLI (mean age: 9 years) who were matched for chronological age, sex, and academic abilities in terms of various components of linguistic functioning including prosody. Vocabulary and phonology did not differentiate the groups. However, expressive syntax, pragmatics, and certain features of prosody did distinguish these groups. These investigators reported that more of a developmental delay profile was observed for SLI than for the other groups, in that the SLI group exhibited strong correlations between raw scores on the language measures and chronological age, whereas the AD and PDD-NOS groups did not (except for pragmatic errors for the PDD-NOS group). Demouy et al. [34] interpreted their findings as being indicative of different underlying mechanisms in $\mathrm{AD}$ and SLI, with PDD-NOS having an intermediate profile with some characteristics of each of the other two conditions.

Most of the research comparing SLI and ASD has examined language phenotypes, but there has also been some interest in more global comparisons of autistic features and of specific cognitive profiles. Two recent investigations have examined overlap between children with ASD relative to children with SLI or PLI based on their performance on autism diagnostic measures [35, 17]. Reisinger et al. [17] compared school-aged children with ASD and PLI in terms of 'autism triad' impairments on the Autism Diagnostic Observational Schedule (ADOS) [36] and the Social Communication Questionnaire [37]. The children with ASD had more severe impairments of communication and social interaction than children with PLI, as well as a higher number of restricted and repetitive behaviors and interests; however, these investigators emphasized the commonalities in the ASD and PLI groups based on the fact that both groups presented impairment in all three of the 'autism triad' areas. Similarly, Leyfer et al. [35] reported evidence for overlap in social and communication deficits in SLI and ASD based on a compari- son of performance on the ADOS and Autism Diagnostic Interview-Revised [38]. Specifically, when groups of children with SLI or ASD were matched on nonverbal IQ, results indicated that $41 \%$ of the SLI group met criteria for autism or autism spectrum on the social or communication domains of the ADOS, Autism Diagnostic Interview-Revised, or both. Taylor et al. [39] conducted a review of recent literature to determine whether there is evidence that cognitive profiles of children with SLI and ASD overlap. The aspects of cognitive functioning that were explored were ones that have been identified as deficit areas for children with autism, namely theory of mind, emotion recognition, executive functions, and central coherence. Taylor et al. [39] concluded that the results across studies are mixed and that there is no substantial support for the claim that SLI and ASD have overlapping cognitive phenotypes. Readers are also referred to a recent discussion regarding the relation between language and executive functions in children with ASD as compared to SLI [40].

\section{Neuroimaging Results}

Researchers have debated whether the apparent language similarities between SLI and a subgroup of children with autism who have language impairment actually reflect a common etiology [29, 33, 41-43]. Findings from neuroimaging studies as well as genetic investigations have attempted to shed light on this issue.

In two separate studies using magnetic resonance imaging, Herbert et al. $[44,45]$ demonstrated enlargement of cerebral white matter in children with autism [44] and children with 'developmental language delay' (this term is used in a manner that is generally consistent with the term 'SLI') [45]. In subsequent investigations that directly compared these clinical groups, Herbert et al. [46, 47] have reported similarities with respect to enlargement of the radiate crown (corona radiata) [46] and rightward cerebral cortical asymmetry [47]. Several neuroimaging studies have compared the same set of boys with autism with language impairment (ALI), autism but normal language, SLI, and typical development [48, 49]. De Fossé et al. [48] found that the SLI and ALI boys displayed a significant reversal of volumetric asymmetry in the frontal language association cortex, such that both groups with language impairment had a rightward bias, whereas the groups without language impairment had a leftward bias. These findings indicate that reversal asymmetry in Broca's area is related to language impairment rather than autism diagnosis. Hodge et al. [49] reported finding reversed asymmetry in posterior cerebellar lobule VIIIA in 
boys with language impairment (with and without autism), but not in normal-language boys (with or without autism). Further, they found that scores in language tests correlated with lobule VIIIA asymmetry and with anterior vermis volume. When combined with this laboratory's prior findings of reversed asymmetry in Broca's area, these results provide evidence that ALI and SLI groups display abnormalities relative to controls (a typically developing group and autism group without language impairment) in frontocorticocerebellar circuits implicated in motor control and processing of language, working memory, and attention; this pattern of findings suggests that these neural anomalies are associated with language and cognitive deficits rather than autism per se. However, Hodge et al. [49] point to genetic evidence for overlap in ASD and SLI and suggest that genetic factors which influence the development of cerebral asymmetry may impact the atypical patterns seen in both SLI and ASD.

An international team of investigators (from Belgium, the Netherlands, Italy and the USA) addressed the question of whether there is a common neuroanatomical substrate for the overlapping language phenotypes seen in SLI and ASD-LI, using diffusion tensor imaging techniques [50]. These researchers studied the white matter microstructural properties of the superior longitudinal fascicle (SLF), one of the critical language tracts connecting Broca's area and Wernicke's area. Children with ASD-LI (mean age: 13 years) and age-matched, typically developing controls were compared with children with SLI (mean age: 10 years) and their age-matched controls. Results from standardized language tests confirmed that both clinical groups displayed mixed receptive-expressive language deficits, demonstrating similar linguistic phenotypes at least at a broad level. Diffusion tensor imaging findings revealed no significant differences in mean SLF fractional anisotropy and mean SLF apparent diffusion coefficient values for the ASD-LI group and their control group. Conversely, the mean SLF fractional anisotropy for the SLI group was significantly reduced relative to their controls. These results indicate structural differences in SLI that were not seen in ASD-LI, suggesting different neuroanatomical bases for these disorders.

\section{Genetic Findings}

Behavioral genetic studies examining the overlap between SLI and ASD have yielded mixed results (for a review of potential genetic influences on developmental language disorders see [51]). Familial aggregation stud- ies have demonstrated an increased risk of ASD in siblings of children with SLI $[52,53]$ and an increased risk of SLI in siblings of children with ASD [54]. Despite the fact that the findings of Pickles et al. [52] replicated earlier reports of an elevated risk of ASD in families of children with SLI, their overall results did not support a common etiology for these disorders. Using the Family History Interview [55], Pickles et al. [52] examined communication and social deficits in relatives of probands with SLI, ASD, and Down syndrome (DS; a nonheritable disorder that served as a control for the other clinical groups). Findings indicated that relatives of probands with SLI had more communication deficits than social difficulties compared with ASD and DS relatives. Conversely, relatives of probands with ASD displayed elevated levels of social deficits when compared with SLI-only and DS relatives. A subgroup of the SLI probands were identified as having SLI and ASD - that is, children with SLI who later developed an autistic symptomatology [19, 56]. The relatives of the SLI+ASD subgroup had a higher rate of social deficits than the relatives of the SLI-only subgroup, much like the relatives of the ASD probands. Other genetic research has focused on clinical markers for SLI, with a comparison with ASD. A high heritability of phonological short-term memory deficits as measured by nonword repetition tasks has been clearly demonstrated for SLI $[26,57]$. Although children with SLI and ASD both exhibit deficits in nonword repetition, there is evidence from genetic studies that these deficits are not familial in autism $[58,59]$. A series of studies have indicated that the CNTNAP2 gene is associated with both SLI and autism, suggesting a shared etiology of these conditions or language impairment more broadly (see review by Tomblin [43]). Some quantitative genetic findings have suggested a locus of susceptibility common to ASD and SLI $[60,61]$, but other genetic linkage studies have reported different linkage signals [62].

Several comprehensive review articles have addressed the question of etiological overlap in ASD and SLI [29, 43]. Based on a summary of linguistic, neurobiological, and genetic data, Williams et al. [29] acknowledge certain dimensions of language overlap for children with SLI and ASD at some points in development, but they argue that surface similarities do not mean that the language profiles stem from the same underlying causes. With respect to both neurobiological and genetic data, they contend that the evidence does not support the claim that SLI and ASD are overlapping disorders. Whitehouse et al. [32, 59] have expressed this same view concerning the relationship between these disorders. A review paper by Tomblin [43] 
considers the relationship between SLI and ASD based on language data, brain imaging findings, and genetic research. Although he contends that partial etiological overlap appears likely, he qualifies this conclusion by pointing out the complexities inherent in this debate, including the heterogeneous nature of SLI and ASD, the fact that features of SLI also occur in other neurodevelopmental disorders, and that the clinical classification schemes that are used necessarily influence the features of the conditions under investigation. Focusing on genetic evidence, Bishop [42] compared etiological models of ASD and SLI. Based on her findings she rejected a 'phenomimicry' account which claims that similarities in these clinical phenotypes are superficial in nature and actually have different underlying causes. Instead, she claimed that results from family studies and molecular genetic research were best explained by a simulated model that postulates an overlapping etiology for SLI and ASD through the incorporation of gene-gene interaction. A recent study by Bartlett et al. [63] provides empirical support for Bishop's [42] hypothesis and computer simulation, suggesting that gene-gene interaction can account for common molecular genetic findings across SLI and ASD while allowing for phenotypic differences related to each diagnosis.

\section{Summary of SLI-ASD Comparisons}

After more than a decade of investigation, the empirical findings do not offer a clear answer regarding the exact nature of the relationship between ASD and SLI. Certainly, both disorders entail language and communication problems (as do a number of other neurodevelopmental disorders) yet each is defined by other distinct diagnostic criteria. Unlike disorders that have an identified genetic basis (e.g. fragile X syndrome, DS) or an obvious sensory component (e.g. language impairment associated with hearing loss), both ASD and SLI have an unknown etiology. When subgroups of children from these two different diagnostic categories appear to display intriguingly similar behavior in certain areas of language and/or cognitive functioning, researchers have attempted to ascertain the boundaries of the overlap with respect to the behavioral phenotypes and follow these clues in search of a shared etiology. Whether or not the bulk of the evidence supports the notion of shared etiology between SLI and ASD is a matter of considerable debate $[29,42,43]$, as is the question of whether investigation of this particular cross-group comparison is even a productive line of research [29].

\section{Terminological Issues}

Adding to the complexity of this area of research is the fact that the classification schemes used to identify SLI and ASD necessarily impact the extent to which these disorders are viewed as overlapping [43], yet these schemes are not entirely consistent. In fact, based on a large-scale 3-year investigation sponsored by the British government, referred to as the Better Communication Research Programme, a group of researchers in England noted that the lack of a clear and consistent terminology regarding language and communication disorders across research, clinical, and educational settings within and across different countries is very problematic [64].

Diagnostic criteria for autism and language disorders have been set forth by the 10th revision of the International Statistical Classification of Diseases and Related Health Problems developed by the World Health Organization (ICD-10) [4]. Alternately, these disorders are identified within the USA and certain other countries using the Diagnostic and Statistical Manual of Mental Disorders (DSM) published by the American Psychiatric Association. The diagnostic criteria for language impairment and autism provided by the 4 th edition of the DSM (DSM-IV) [65] and the ICD-10 were fairly compatible with respect to autism and language disorders. Both the ICD-10 and DSM-IV classifications include subgroup distinctions based on language modality, i.e. receptive language disorder and expressive language disorder, and provide similar diagnostic classifications for $\mathrm{AD}$, Rett's syndrome, other childhood disintegrative disorder, Asperger's syndrome, and PDD-NOS. However, there is considerably less compatibility across the ICD-10 and new DSM-5 classifications [66] for these two disorders. The category of 'communication disorders' in the DSM5 includes classifications of 'language disorder' (without separate codes to distinguish between receptive or expressive subtypes) and 'social communication disorder', which appears to be equivalent to the term PLI in the research literature. More substantive changes have occurred in the DSM-5 guidelines for autism diagnosis such that Rett's syndrome has been removed and the remaining classifications have been merged under the single term 'autism spectrum disorder', with further distinctions being made on the basis of severity.

In addition to inconsistencies in these two sets of official diagnostic criteria, varying terminology is used by researchers and clinicians. Conti-Ramsden and Botting [18] noted that a shift has occurred over time in the boundary between SLI and pervasive developmental dis-
72

Folia Phoniatr Logop 2013;65:68-77 DOI: $10.1159 / 000353896$
Weismer 
order within the UK. Children identified as having PLI appear to fall between typical SLI and autism classifications. The PLI classification has never been widely used in the USA among researchers or clinical practitioners. Now that this classification, labeled 'social communication disorder', is identified in the new DSM-5, it will be interesting to see how this unfolds and whether children meeting these criteria will ultimately be identified and receive services. Although the term SLI is commonly used internationally within the research literature, it is not used in clinical or educational settings - at least not within the USA. In fact, when there was consideration of including SLI in the DSM-5 as a separate classification of communication disorder, the American Speech-Language-Hearing Association strongly argued against this terminology, saying that it is not used clinically and that most speech-language therapists do not have cognitive/ IQ data on which to make this diagnosis [67]. There were a series of contentious debates among researchers and clinicians from the USA, Australia, France, and elsewhere regarding the revisions to the autism diagnostic scheme adopted by the DSM-5 [34, 68-71]. Interestingly, Dr. Thomas Insel, Director of the National Institute of Mental Health, a division within the National Institutes of Health in the USA, came out with strong criticism of the DSM criteria, claiming that while providing reliability in their use of terminology, the DSM diagnostic categories lacked validity. Dr. Insel stated: 'Indeed, symptom-based diagnosis, once common in other areas of medicine, has been largely replaced in the past half century as we have understood that symptoms alone rarely indicate the best choice of treatment' [72]. As an alternative, the National Institute of Mental Health has launched a 10-year project referred to as the Research Domain Criteria Project, in which researchers funded by this agency will be required to include patients across DSM categories or subdivide current categories and to collect cognitive, imaging, genetic, or physiologic data to determine how these cluster with respect to response to treatment [73].

\section{Clinical Implications for Diagnosis and Treatment}

\section{Diagnosis}

Even if there were complete agreement with respect to classification schemes, the task of implementing classifications in clinical practice for the purpose of diagnosis is not always straightforward. This is not only true for differential diagnosis at very young ages, but also at various

Developmental Language Disorders points in development. For example, Tierney et al. [74] present a discussion between physicians regarding 2 case examples of 7-year-old boys to illustrate difficulties in distinguishing borderline cases of SLI and ASD. This can be a problem for physicians, psychologists, and speechlanguage therapists.

One approach that may be useful for the purpose of differential diagnosis is to focus on the points of distinction that have been noted in the research literature comparing SLI and ASD, as a supplement to the symptoms and descriptions detailed by the ICD-10 or DSM-5. Studies have found that severe receptive language deficits (as opposed to primarily expressive language deficits) are typically indicative of ASD rather than SLI or early language delay $[10,75,76]$. Prosodic deficits have been reported in ASD across various languages [34, 77-79] and have been shown to distinguish between children with ASD and SLI [34]. In this regard, Demouy et al. [34] noted the usefulness of automated approaches to assessing prosodic/vocal characteristics of children in naturalistic settings [80, 81]. Error patterns on nonword repetition tasks, rather than overall accuracy levels, have been shown to differentiate ASD and SLI groups [31, 32]; thus, error analysis or use of a nonword repetition task - recently developed by Williams et al. [33] - which manipulates nonword length, cluster position, and presence or absence of a suffix could be a helpful means of distinguishing between these disorders. Manolitsi and Botting [75] assessed language abilities in Greek-speaking children with SLI and ASD, using standardized tests and narrative language samples. Their findings suggest that narrative assessment is a useful tool for identifying qualitative differences in language abilities between these groups that may not be revealed on standardized measures. A largescale study of Italian-speaking children also found that narrative language samples were useful in distinguishing morphological and syntactic deficits in children with SLI compared with typically developing children [82]. Norbury and Bishop [83] examined narratives produced by English-speaking children with SLI, PLI, and high-functioning autism. They found that the diagnostic groups were differentiated by their use of referencing skills such that children with autism produced more ambiguous nouns and pronouns than the other groups; however, overall, there was a good deal of overlap across groups, especially with respect to structural language abilities. Of course, when attempting to assess language disorders, it is important to keep in mind that language-specific features will impact how disorders are manifested across different languages [84]. 


\section{Treatment}

When considering interventions, it is important to be concerned with etiology even though there is a complex dynamic between genes, brain, and behavior. Etiologic factors are especially important when considering pharmaceutical treatments; however, nearly all of the interventions for language and communication deficits involve behavioral approaches. Can different types of interventions be used effectively with different diagnostic groups? Perhaps this is where research findings regarding points of overlap or similarity across the children with ASD, SLI, and PLI might be instructive. Based on the national study undertaken by investigators in England as part of the Better Communication Research Programme, it was reported that children's individual characteristics, rather than their classification, predicted their learning needs. However, it was classification (language impairment vs. ASD) that determined the amount of resources they received [64]. Reisinger et al. [17] have stressed the importance of similarities between ASD and PLI groups with respect to intervention. They concluded that sorting out diagnostic distinctions is important from a 'neurodevelopmental perspective' but suggest that it may be equally important in certain cases to disregard categorical boundaries and instead focus on individual areas of strengths and deficits. They conclude that the commonalities across these groups may be more important than their differences from an intervention standpoint. Reisinger et al. [17] suggest that children with PLI, like children with ASD, could benefit from treatment focused on social skill development and may be at risk of being bullied, with associated mental health problems. It could similarly be argued that children with ASD-LI who have deficits in grammatical aspects of language [85] like those seen in SLI may respond to the same types of interventions focused on facilitating grammatical acquisition through intensive modeling, sentence recasting, and expansions. Consider for a moment cases in which the etiology of language disorders is known to be different, such as DS and SLI. There is a clear genetic basis for DS in which language impairment is associated with cognitive delay, whereas SLI has no general cognitive delay but also presents with an overall pattern of delayed language. Caselli et al. [86] compared language abilities of Italianspeaking children with DS and SLI who were matched on mental age. Their findings revealed a number of commonalities across these groups in lexical and morphosyntactic areas, including striking similarities in morphosyntactic error patterns. Research has also demonstrated that both of these groups exhibit difficulties in auditory pro- cessing and working memory thought to be related to their linguistic difficulties [87, 88]; therefore, they may benefit from similar interventions targeted on this area. As suggested by the new initiative proposed by the $\mathrm{Na}$ tional Institutes of Health, it may be fruitful to cross diagnostic categories in order to focus on commonalities in specific cognitive underpinnings of language and communication deficits as they relate to treatment response.

\section{Concluding Thoughts}

Despite the fact that some researchers have questioned the utility of studies comparing ASD and SLI [29], it can be argued that information gained from these investigations has important clinical implications with respect to differential diagnosis and intervention. Even though the findings concerning overlap between these disorders are decidedly mixed, they do point to particular areas of commonality and distinction. Given the lack of consistent terminology and diagnostic criteria, results from studies that have directly contrasted these diagnostic groups provide an additional evidence base on which to draw. From a global perspective, it is critical to understand the extent to which cross-cultural issues impact the identification and subsequent treatment - of developmental disorders [89-91]. Norbury and Sparks [90] provide an in-depth and thought-provoking discussion of how cultural issues influence whether individual variations in the behavioral symptoms manifested in SLI and ASD are viewed simply as differences or disorders, and they emphasize the need for cross-cultural studies to extend the largely North American and European view of these disorders. Whether or not ASD, SLI, and PLI are ultimately found to have a shared etiology, evidence should be gathered to determine if common interventions geared towards points of language or cognitive or social overlaps among these groups yield a similar response to treatment.

\section{Acknowledgement}

Support provided by NIH grant R01DC011750.
Weismer 


\section{References}

1 Bishop DVM: Uncommon Understanding. Hove, Psychology Press, 1997.

2 Leonard LB: Children with Specific Language Impairment. MIT Press, 2000.

3 Rapin I, Dunn M, Allen DA: Developmental language disorders; in Segalowitz SJ, Rapin I (eds): Handbook of Neuropsychology. Amsterdam, Elsevier, 2003, vol 8, chap 2.

4 ICD-10 International Statistical Classification of Diseases and Related Health Problems, ed 2, rev 10. World Health Organization, 2005.

5 Ellis Weismer S: Specific language impairment; in Cummings L (ed): Handbook of Communication Disorders. Cambridge, Cambridge UP, in press, chap 5 .

6 Bishop DVM, Norbury CF: Exploring the borderlands of autistic disorder and specific language impairment: a study using standardized diagnostic instruments. J Child Psychol Psychiatry 2002;43:917-929.

7 Botting N, Conti-Ramsden G: Pragmatic language impairment without autism. Autism 1999;3:371-396.

8 Lord C, Risi S, Pickles A: Trajectory of language development in autistic spectrum disorders; in Rice M, Warren S (eds): Developmental Language Disorders: From Phenotypes to Etiologies. Mahwah, Erlbaum, 2004, pp 1-38.

$\checkmark 9$ Thurm A, Lord C, Lee L, Newschaffer C: Predictors of language acquisition in preschool children with autism spectrum disorders. J Autism Dev Disord 2007;37:1721-1734.

$\checkmark 10$ Bartak L, Rutter M, Cox A: A comparative study of infantile autism and specific developmental receptive language disorder. I The children. Brit J Psychiatry 1975;126: 127-145.

11 Cantwell DP, Baker L, Rutter M, Mawhood L: Infantile autism and developmental receptive dysphasia: a comparative follow-up into middle childhood. J Autism Dev Disord 1989;19: 19-31.

$>12$ Bishop DVM, Chan J, Adams C, Hartley J, Weir F: Conversational responsiveness in specific language impairment: evidence of disproportionate pragmatic difficulty in a subset of children. Dev Psychopathol 2000;12: 177-199.

13 Fujiki M, Brinton B: Pragmatics and social communication in child language disorders; in Schwartz RG (ed): Handbook of Child Language Disorders. New York, Psychology Press, 2009, pp 406-423.

14 Bishop DVM: Pragmatic language impairment: a correlate of SLI, a distinct subgroup, or part of the autistic continuum? In Bishop DVM, Leonard LB (eds): Speech and Language Impairments in Children. Hove, Psychology Press, 2000, pp 99-113.

15 Conti-Ramsden G, Botting N: Characteristics of children attending language units in England: a national study of 7 -year-olds. Int J Lang Commun Disord 1999;34:359-366.
16 Bishop DVM: Autism and specific language impairment: categorical distinction or continuum? In Bock G, Goode J (eds): Autism: Neural Basis and Treatment Possibilities. Novartis Foundation Symposia 251. Chichester, Wiley, 2003, pp 213-226.

17 Reisinger LM, Cornish KM, Fombonne É: Diagnostic differentiation of autism spectrum disorders and pragmatic language impairment. J Autism Dev Disord 2011;41:16941704.

18 Conti-Ramsden G, Botting N: Social difficulties and victimization in children with SLI at 11 years of age. J Speech Lang Hear Res 2004; 47:145-161.

19 Conti-Ramsden G, Simkin Z, Botting N: The prevalence of autistic spectrum disorders in adolescents with a history of specific language impairment (SLI). J Child Psychol Psychiatry 2006; 47:621-628.

20 Geurts HM, Embrechts M: Language profiles in ASD, SLI, and ADHD. J Autism Dev Disord 2008;38:1931-1943.

21 Kjelgaard MM, Tager-Flusberg H: An investigation of language impairment in autism: implications for genetic subgroups. Lang Cogn Process 2001;16:287-308.

-22 Loucas T, Charman T, Pickles A, Simonoff E, Chandler S, Meldrum D, Baird G: Autistic symptomatology and language ability in autism spectrum disorder and specific language impairment. J Child Psychol Psychiatry 2008; 49:1184-1192.

23 Roberts JA, Rice ML, Tager-Flusberg H: Tense marking in children with autism. Appl Psycholinguist 2004;25:429-448.

24 Tager-Flusberg H, Joseph RM: Identifying neurocognitive phenotypes in autism. Philos Trans R Soc Lond B Biol Sci 2003;358:303-314.

25 Rice ML: Grammatical symptoms of specific language impairment; in Bishop DVM, Leonard LB (eds): Speech and Language Impairments in Children: Causes, Characteristics, Intervention and Outcome. Hove, Psychology Press, 2000, pp 17-34.

26 Bishop DVM, North T, Donlan C: Nonword repetition as a behavioural marker for inherited language impairment: evidence from a twin study. J Child Psychol Psychiatry 1996; 37:391-403.

-27 McGregor KK, Berns AJ, Owen AJ, Michels SA, Duff D, Bahnsen AJ, Lloyd M: Associations between syntax and the lexicon among children with or without ASD and language impairment. J Autism Dev Disord 2012;42:35-47.

28 Ellis Weismer S, Gernsbacher MA, Stronach S, Karasinski C, Eernisse ER, Venker CE, Sindberg H: Lexical and grammatical skills in toddlers on the autism spectrum compared to late talking toddlers. J Autism Dev Disord 2011;41:1065-1075.

29 Williams D, Botting N, Boucher J: Language in autism and specific language impairment: where are the links? Psychol Bull 2008;134: 944-963.
30 Charman T: Developmental approaches to understanding and treating autism. Folia Phoniatr Logop 2010;62:166-177.

- 31 Riches NG, Loucas T, Baird G, Charman T, Simonoff E: Non-word repetition in adolescents with specific language impairment and autism plus language impairments: a qualitative analysis. J Commun Disord 2011;44:2336.

32 Whitehouse AJ, Barry JG, Bishop DVM: Further defining the language impairment of autism: is there a specific language impairment subtype? J Commun Disord 2008;41:319336.

33 Williams D, Payne H, Marshall C: Non-word repetition impairment in autism and specific language impairment: evidence for distinct underlying cognitive causes. J Autism Dev Disord 2013;43:404-417.

- 34 Demouy J, Plaza M, Xavier J, Ringeval F, Chetouani M, Périsse D, Chauvin D, Viaux S, Golse B, Cohen D, Robel L: Differential language markers of pathology in autism, pervasive developmental disorder not otherwise specified and specific language impairment. Res Autism Spectr Disord 2011;5:1402-1412.

- 35 Leyfer OT, Tager-Flusberg HT, Dowd M, Tomblin JB, Folstein SE: Overlap between autism and specific language impairment: comparison of Autism Diagnostic Interview and Autism Diagnostic Observation Schedule scores. Autism Res 2008;1:284-296.

36 Lord C, Rutter, M, di Lavore PC, Risi S: Autism Diagnostic Observation Schedule Manual. Los Angeles, Western Psychological Services, 2002.

37 Rutter M, Bailey A, Lord C: Social Communication Questionnaire Manual. Los Angeles, Western Psychological Services, 2003.

38 Rutter M, le Couteur A, Lord C: Autism Diagnostic Interview-Revised. Los Angeles, Western Psychological Services, 1994.

39 Taylor LJ, Maybery MT, Whitehouse AJO: Do children with specific language impairment have a cognitive profile reminiscent of autism? A review of the literature. J Autism Dev Disord 2012;42:2067-2083.

40 Akbar M, Loomis R, Paul R: The interplay of language on executive functions in children with ASD. Res Autism Spectr Disord 2013;7: 494-501.

41 Bishop DVM: Specific language impairment, dyslexia and autism: using genetics to unravel their relationship; in Norbury CF, Tomblin JB, Bishop DVM (eds): Understanding Developmental Language Disorders: From Theory to Practice. Hove, Psychology Press, 2008, pp 67-78.

42 Bishop DVM: Overlaps between autism and language impairment: phenomimicry or shared etiology? Behav Genet 2010;40:618629 .

43 Tomblin JB: Co-morbidity of autism and SLI: kinds, kin and complexity. Int J Lang Commun Disord 2011;46:127-137. 
-44 Herbert MR, Harris G, Adrien K, Ziegler DA, Makris N, Kennedy D, Lange N, Chabris C, Bakardjiev A, Hodgson J, Takeoka M, TagerFlusberg H, Caviness V Jr: Abnormal asymmetry in language association cortex in autism. Ann Neurol 2002;52:588-596.

-45 Herbert MR, Ziegler DA, Makris N, Bakardjiev A, Hodgson J, Adrien KT, Kennedy DN, Filipek PA, Caviness VS Jr: Larger brain and white matter volumes in children with developmental language disorder. Dev Sci 2003;6:F11-F22.

-46 Herbert MR, Ziegler DA, Makris N, Filipek PA, Kemper TL, Normandin JJ, Sanders HA, Kennedy DN, Caviness VS Jr: Localization of white matter volume increase in autism and developmental language disorder. Ann Neurol 2004;55:530-540.

-47 Herbert MR, Ziegler DA, Deutsch CK, O'Brien LM, Kennedy DN, Filipek PA, Bakardjiev AI, Hodgson J, Takeoka M, Makris $\mathrm{N}$, Caviness VS Jr: Brain asymmetries in autism and developmental language disorder: a nested whole-brain analysis. Brain 2005;128: 213-226.

48 de Fossé L, Hodge SM, Makris N, Kennedy DN, Caviness VS Jr, McGrath L, Steele S, Ziegler DA, Herbert MR, Frazier JA, TagerFlusberg H, Harris GJ: Language-association cortex asymmetry in autism and specific language impairment. Ann Neurol 2004;56:757766.

-49 Hodge SM, Makris N, Kennedy DN, Caviness VS Jr, Howard J, McGrath L, Steele S, Frazier JA, Tager-Flusberg H, Harris GJ: Cerebellum, language, and cognition in autism and specific language impairment. J Autism Dev Disord 2010;40:300-316.

50 Verhoeven JS, Rommel N, Prodi E, Leemans A, Zink I, Vandewalle E, Noens I, Wagemans J, Steyaert J, Boets B, van de Winckel A, de Cock P, Lagae L, Sunaert S: Is there a common neuroanatomical substrate of language deficit between autism spectrum disorder and specific language impairment? Cereb Cortex 2012;22:2263-2271.

-51 Fisher SE: Molecular windows into speech and language disorders. Folia Phoniatr Logop 2007;59:130-140.

52 Pickles A, St Clair MC, Conti-Ramsden G: Communication and social deficits in relatives of individuals with SLI and relatives of individuals with ASD. J Autism Dev Disord 2013;43:156-167.

- 53 Tomblin JB, Hafeman L, O’Brien M: Autism and autism risk in siblings of children with specific language impairment. Int J Lang Commun Disord 2003;38:235-250.

- 54 Folstein SE, Mankoski RE: Chromosome 7q: where autism meets language disorder? Am J Hum Genet 2000;67:278-281.

-55 Bolton P, Macdonald H, Pickles A, Rios P, Goode S, Crowson M, Bailey A, Rutter M: A case-control family history study of autism. J Child Psychol Psychiatry 1994;35:877-900.
St Clair M, Durkin K, Conti-Ramsden G, Pickles A: Growth of reading skills in children with a history of specific language impairment: the role of autistic symptomatology and language-related abilities. Br J Dev Psychol 2010;28:109-131.

57 Falcaro M, Pickles A, Newbury DF, Addis L, Banfield E, Fisher SE, Monaco AP, Simkin Z, Conti-Ramsden G, SLI Consortium: Genetic and phenotypic effects of phonological shortterm memory and grammatical morphology in specific language impairment. Genes Brain Behav 2008;7:393-402.

58 Bishop DVM, Maybery M, Wong D, Maley A, Hill W, Hallmayer J: Are phonological processing deficits part of the broad autism phenotype? Am J Med Genet B Neuropsychiatr Genet 2004;128B:54-60.

59 Whitehouse AO, Barry JG, Bishop DM: The broader language phenotype of autism: a comparison with specific language impairment. J Child Psychol Psychiatry 2007;48: 822-830.

60 Warburton P, Baird G, Chen W, Morris K, Jacobs BW, Hodgson S, Docherty Z: Support of linkage of autism and specific language impairment to $7 \mathrm{q} 3$ from two chromosome rearrangements involving band 7q31. Am J Med Genet 2000;96:228-234.

61 O'Brien E, Zhang X, Nishimura C, Tomblin JB, Murray JC: Association of specific language impairment (SLI) to the region of $7 \mathrm{q} 31$. Am J Med Genet 2003;72:1536-1543.

62 Buxbaum JD, Silverman JM, Smith CJ, Kilifarski M, Reichert J, Hollander E, Lawlor BA, Fitzgerald M, Greenberg DA, Davis KL: Evidence for a susceptibility gene for autism on chromosome 2 and for genetic heterogeneity. Am J Med Genet 2001;68:1514-1520.

63 Bartlett CW, Flax JF, Fermano Z, Hare A, Hou L, Petrill SA, Buyske S, Brzustowicz LM: Gene $\times$ gene interaction in shared etiology of autism and specific language impairment. Biol Psychiatry 2012;72:692-699.

64 Better Research Communication Programme. http://www2.warwick.ac.uk/fac/soc/cedar/ better (accessed June 1, 2013).

65 Diagnostic and Statistical Manual of Mental Disorders, ed 4 (DSM-IV). Arlington, American Psychiatric Association, 1994. http:// www.psychiatry.org/practice/dsm/dsm-iv-tr (accessed May 15, 2013).

66 Diagnostic and Statistical Manual of Mental Disorders, ed 5 (DSM-5). Arlington, American Psychiatric Association, 2013. http:// www.dsm5.org/Pages/Default.aspx (accessed May 15, 2013).

67 American Speech-Language-Hearing Association: DSM-V development: ASHA comments. 2011. http://www.asha.org/uploadedFiles/June-2011-DSM-V-DevelopmentComments.pdf (accessed May 15, 2013).

68 Happé F: Criteria, categories, and continua: autism and related disorders in DSM-5. J Am Acad Child Adolesc Psychiatry 2011;50:540542.
69 Huerta M, Bishop S, Duncan A, Hus V, Lord C: Application of DSM-5 criteria for autism spectrum disorders to three samples of children with DSM-IV diagnoses of pervasive developmental disorders. Am J Psychiatry 2012; 169:1056-1064.

70 Mandy WPL, Charman T, Skuse D: Testing the construct validity of proposed DSM- 5 criteria for autism spectrum disorder. J Am Acad Child Adolesc Psychiatry 2012;51:41-50.

71 Whitehouse A: DSM-V and the changing fortunes of autism and related disorders. 2012. http://theconversation.edu.au/dsm-v-andthe-changing-fortunes-of-autism-and-related-disorders-5071 (accessed June 1, 2013).

72 Insel T: Director's blog: transforming diagnosis. 2013. http://www.nimh.nih.gov/about/director/2013/transforming-diagnosis.shtml (accessed June 1, 2013).

73 Pappas S: National Institute of Mental Health no longer will use DSM diagnoses in studies. 2013. http://www.cbsnews.com/8301-204 162-57582839/national-institute-of-mentalhealth-no-longer-will-use-dsm-diagnosesin-studies/ (accessed May 25, 2013).

74 Tierney CD, Gupta VB, del Angel AP, Augustyn $\mathrm{M}$ : Teasing out specific language impairment from an autism spectrum disorder. J Dev Behav Pediatr 2012;33:272-274.

75 Manolitsi M, Botting N: Language abilities in children with autism and language impairment: using narrative as a additional source of clinical information. Child Lang Teach Ther 2011;27:39-55.

76 Paul R, Ellis Weismer S: When is late talking a matter for concern? In Rescorla L, Dale P (eds): Late Talkers: Research to Practice. Baltimore, Brookes, in press.

77 Eigsti IM, Schuh J, Mencl E, Schultz RT, Paul R: The neural underpinnings of prosody in autism. Child Neurospychol 2012;18:600617.

78 Paul R, Augustyn A, Klin A, Volkmar F: Perception and production of prosody by speakers with autism spectrum disorders. J Autism Dev Disord 2005;35:205-220.

-79 Paul R, Bianchi N, Augustyn A, Klin A, Volkmar F: Production of syllable stress in speakers with autism spectrum disorders. Res Autism Spectr Disord 2008;2:110-124.

80 Oller DK, Niyogi P, Gray S, Richards JA, Gilkerson J, Xu D, Yapanel U, Warren SF: Automated vocal analysis of naturalistic recordings from children with autism, language delay, and typical development. Proc Natl Acad Sci USA 2010;107:13354-13359.

-81 Warren SF, Gilkerson J, Richards JA, Oller DK, Xu D, Yapanel U, Gray S: What automated vocal analysis reveals about the vocal production and language learning environment of young children with autism. J Autism Dev Disord 2010;40:555-569.

82 Marini A, Tavano A, Fabbro F: Assessment of linguistic abilities in Italian children with specific language impairment. Neuropsychologia 2008;46:2816-2823. 
83 Norbury CF, Bishop DVM: Narrative skills of children with communication impairments. Int J Lang Commun Disord 2003;38:287-313.

84 Leonard LB: Cross-linguistic studies of child language disorders; in Schwartz RG (ed): Handbook of Child Language Disorders. New York, Psychology Press, 2009, pp 308-324.

85 Eigsti IM, de Marchena AB, Schuh JM, Kelley E: Language acquisition in autism spectrum disorders: a developmental review. Res Autism Spectr Disord 2011;5:681-691.

86 Caselli MC, Monaco L, Trasciani M, Vicari S: Language in Italian children with Down syndrome and with specific language impairment. Neuropsychology 2008;22:27-35.
87 Jarrold C, Baddeley AD, Phillips CE: Verbal short-term memory in Down syndrome: a problem of memory, audition, or speech? J Speech Lang Hear Res 2002;45:531-544.

88 Montgomery JW, Magimairaj BM, Finney MC: Working memory and specific language impairment: an update on the relation and perspectives on assessment and treatment. Am J Speech Lang Pathol 2010;19:78-94.

89 Matson JL, Worley JA, Kozlowski AM, Chung K-M, Jung W, Yang J-W: Cross cultural differences of parent reported social skills in children with autistic disorder: an examination between South Korea and the United States of America. Res Autism Spectr Disord 2012;6:971-977.
90 Norbury CF, Sparks A: Difference or disorder? Cultural issues in understanding neurodevelopmental disorders. Dev Psychol 2013; 49:45-58.

91 Zachor D, Yang J-W, Itzchak EB, Furniss F, Pegg E, Matson JL, Horovitz M, Sipes M, Chung K-M, Jung W: Cross-cultural differences in comorbid symptoms of children with autism spectrum disorders: an international examination between Isreal, South Korea, the United Kingdom and the United States of America. Dev Neurorehabil 2011;14:215220 